Keywords: Hodgkin lymphoma; colorectal cancer; radiation therapy; chemotherapy; procarbazine; second malignant neoplasm; long-term complications

\title{
Infradiaphragmatic irradiation and high procarbazine doses increase colorectal cancer risk in Hodgkin lymphoma survivors
}

Anna M van Eggermond ${ }^{1}$, Michael Schaapveld ${ }^{1,2}$, Cécile PM Janus ${ }^{3}$, Jan Paul de Boer ${ }^{4}$, Augustinus DG Krol ${ }^{5}$, Josée M Zijlstra ${ }^{6}$, Richard WM van der Maazen ${ }^{7}$, Leontien $C$ Kremer $^{8}$, Monique E van Leerdam ${ }^{9}$, Marieke WJ Louwman ${ }^{2}$, Otto Visser ${ }^{2}$, Marie L De Bruin ${ }^{10}$, Berthe MP Aleman ${ }^{11}$ and Flora E van Leeuwen ${ }^{*, 1}$

${ }^{1}$ Department of Epidemiology, The Netherlands Cancer Institute, Plesmanlaan 121, Amsterdam 1066 CX, The Netherlands; ${ }^{2}$ Netherlands Comprehensive Cancer Organisation (IKNL), Hoog Catharijne, Godebaldkwartier 419, Utrecht 3511 DT, The Netherlands; ${ }^{3}$ Department of Radiation Oncology, Erasmus MC Cancer Institute, 's-Gravendijkwal 230, Rotterdam 3015 CE, The Netherlands; ${ }^{4}$ Department of Medical Oncology, The Netherlands Cancer Institute, Plesmanlaan 121, Amsterdam 1066 CX, The Netherlands; ${ }^{5}$ Division of Radiation Oncology, Leiden University Medical Center, Albinusdreef 2, Leiden 2333 ZA, The Netherlands; ${ }^{6}$ Department of Hematology, VU University Medical Center, De Boelelaan 1117, Amsterdam 1081 HV, The Netherlands; ${ }^{7}$ Department of Radiation Oncology, Radboud University Medical Centre, Geert Grooteplein Zuid 10, Nijmegen 6525 GA, The Netherlands; ${ }^{8}$ Department of Pediatric Oncology, Emma Children's Hospital/Academic Medical Center, Meibergdreef 9, Amsterdam-Zuidoost 1105 AZ, The Netherlands; ${ }^{9}$ Department of Gastroenterology and Hepatology, The Netherlands Cancer Institute, Amsterdam, The Netherlands; ${ }^{10}$ Department of Pharmacy, Faculty of Health and Medical Science (CORS), University of Copenhagen, Universitetsparken 2, Copenhagen 2100, Denmark and ${ }^{11}$ Department of Radiation Oncology, The Netherlands Cancer Institute, Plesmanlaan 121, Amsterdam 1066 CX, The Netherlands

Background: Hodgkin lymphoma $(\mathrm{HL})$ survivors are at increased risk of second malignancies, but few studies have assessed colorectal cancer (CRC) risk after HL treatment. We assessed long-term, subsite-specific CRC risk associated with specific radiation fields and chemotherapy regimens.

Methods: In a Dutch cohort of 3121 5-year HL survivors treated between 1965 and 1995, subsite-specific CRC incidence was compared with general population rates. Treatment effects were quantified by Cox regression analyses.

Results: After a median follow-up of 22.9 years, 55 patients developed CRC. The standardized incidence ratios (SIR) was 2.4-fold increased (95\% confidence interval $(95 \% \mathrm{Cl}) 1.8-3.2)$, leading to 5.7 excess cases per 10000 patient-years. Risk was still increased 30 years after HL treatment (SIR: 2.8; 95\% Cl: 1.6-4.6). The highest (SIR: 6.5, 95\% Cl: 3.3-11.3) was seen for transverse colon cancer (15.0 (95\% Cl: 4.3-40.8) after inverted-Y irradiation). A prescribed cumulative procarbazine dose $>4.2 \mathrm{~g} \mathrm{~m}^{-2}$ was associated with a 3.3-fold higher CRC risk (95\% Cl: 1.8-6.1) compared to treatment without procarbazine. Patients receiving $>4.2 \mathrm{~g} \mathrm{~m}^{-2}$ procarbazine and infradiaphragmatic radiotherapy had a hazard ratio of $6.8(95 \% \mathrm{Cl}$ : $3.0-15.6)$ compared with patients receiving neither treatment, which is significantly higher than an additive joint effect $\left(P_{\text {additivity }}=0.004\right)$.

Conclusions: Colorectal cancer surveillance should be considered for HL survivors who received Infradiaphragmatic radiotherapy and a high cumulative procarbazine dose.

*Correspondence: Dr FE van Leeuwen; E-mail: f.v.leeuwen@nki.nl

Received 28 November 2016; revised 27 March 2017; accepted 25 May 2017; published online 20 June 2017

(C) 2017 Cancer Research UK. All rights reserved 0007-0920/17 
Due to the introduction of multi-agent chemotherapy and the continuing improvements in radiation techniques, Hodgkin lymphoma (HL) has become the prototype of a curable malignancy. Currently, the 10 -year disease-specific survival is more than $85 \%$ for patients diagnose before 55 years of age (IKNL, 2012). As a result of this favourable prognosis, there is a growing population of HL survivors at risk of long-term complications caused by radiation therapy and chemotherapy. The risk of solid malignancies after HL treatment, especially risk of breast and lung cancer, has been studied extensively (Swerdlow et al, 2000; van Leeuwen et al, 2000; Dores et al, 2002; Ng et al, 2002; Travis et al, 2002; Travis et al, 2003; Hodgson et al, 2007; De Bruin et al, 2009; van den Belt-Dusebout et al, 2009; Swerdlow et al, 2011; Reulen et al, 2011; Swerdlow et al, 2012; Morton et al, 2013; Dores et al, 2014; Schaapveld et al, 2015). Although colorectal cancer (CRC) is the third most common solid malignancy in HL survivors (Hodgson et al, 2007; Schaapveld et al, 2015), so far few studies have specifically examined risk factors for CRC after HL treatment (Birdwell et al, 1997; Hodgson et al, 2007).

Colon and rectal cancers are often grouped together as they share genetic and epidemiological features (Schottenfeld Winawer, 1982; Network, 2012). Among Japanese atomic bomb survivors increased risk of colon, but not rectum cancer, emerged from 10 years after exposure (Nakatsuka et al, 1992; Nakachi et al, 2006; Preston et al, 2007). Excess rectum cancer risk was found after exposure to higher radiation doses (Land, 1986). Although in atomic bomb survivors, colon subsites showed equal sensitivity to radiation (Nakatsuka et al, 1992); studies of CRC risk among medically-irradiated subjects are complicated by the fact that the colon extends over a large part of the abdomen, and depending upon the radiation techniques, may receive markedly non-uniform doses. Surprisingly, CRC risk has not previously been assessed specifically for colorectal subsites.

Procarbazine has been shown to increase the risk of stomach (van den Belt-Dusebout et al, 2009; Morton et al, 2013) and lung cancer (Swerdlow et al, 2001; Travis et al, 2002) in HL patients. Although Morton and colleagues found statistically significant associations of stomach cancer risk with exposure to procarbazine or dacarbazine but not with other alkylating agents, in the study by Travis and colleagues lung cancer risk was associated both with exposure to mechlorethamine or procarbazine. It is unknown whether chemotherapy also affects CRC risk among HL survivors. However, alkylating agent exposure was associated with an 8.8-fold increased risk of CRC among childhood cancer survivors (9 out of 19 CRC diagnosed in childhood HL survivors) treated at St Jude Children's Research Hospital (Nottage et al, 2012). Similarly, Henderson and colleagues previously reported that procarbazine independently increased risk, potentially in a dose-response manner, of gastrointestinal malignancies in childhood cancer survivors treated with abdominal irradiation (Henderson et al, 2012). Of note, out of 45 gastrointestinal malignancies, 20 were diagnosed among HL survivors and 24 were colorectal cancers. In this study, we therefore assessed the long-term subsite-specific risk of CRC after HL treatment, taking into account radiation fields and cumulative dose of alkylating agents, in a large multicenter Dutch cohort comprising 3121 5-year survivors of HL.

\section{PATIENTS AND METHODS}

Our cohort comprised of HL patients treated in seven Dutch University Hospitals or Cancer Centers and in the affiliated hospitals of the former population-based Eindhoven Cancer Registry. Patient selection and the data collection methods have been described in detail previously (van Leeuwen et al, 2000; De Bruin et al, 2009; Schaapveld et al, 2015). Briefly, patients were younger than 51 years at HL treatment (range: 3.6-50.9), first treated between 1965 and 1995 with radiation therapy and/or chemotherapy, and survived at least 5 years. The detailed treatment data (dates of start of treatment, radiation fields, chemotherapy regimens and number of cycles) were collected from the medical records, both for initial and relapse treatment. Up to 2004 data on second malignancy diagnoses was obtained from the medical records and by contacting general practitioners and attending physicians in other hospitals (94\% complete follow-up) (De Bruin et al, 2009). Additionally, CRCs diagnoses between 2004 and January 2011 were ascertained through linkage with the nationwide PALGA network and registry of histo- and cytopathology (Casparie et al, 2007) and the Netherlands Cancer Registry (NCR). PALGA reached nation-wide coverage in January 1990 and the NCR in January 1989. Completeness of case ascertainment by the NCR is $>98 \%$ (Schouten et al, 1994).

Colorectal cancers were classified according to the International Classification of Diseases for Oncology (ICD-O-3) (WHO, 2000). Colorectal cancers were categorised into ascending colon (including coecum and hepatic flexure), transverse colon (including splenic flexure), descending colon (including sigmoid colon), and rectum (including rectosigmoid junction). Each CRC was classified as 'in field', 'out of field' or 'unknown' based on review of the radiation fields by a radiation oncologist (BMPA). Vital status was obtained up to January 2011 through linkage with the Dutch Central Bureau of Genealogy; $2.7 \%$ of the patients had either emigrated or were otherwise lost-to-follow-up.

Treatment. Over time a wide variety of treatment regimens was used in the cohort. Although primary treatment was usually given in accordance with treatment protocols of the European Organisation for Research and Treatment of Cancer (Favier et al, 2009) treatment for recurrences was generally not standardised. Patients usually received $40 \mathrm{~Gy}$ in 20 fractions when treated with radiation therapy only and $30-36$ Gy in 15-20 fractions when they also received chemotherapy. Mantle field irradiation (mediastinal, axillary and neck nodes) was the most commonly applied radiation field from the early 1970s to the late 1980s. Infradiaphragmatic radiation, commonly including the para-aortic nodes and spleen (para-aortal field), but frequently also the iliac and inguinal nodes (inverted Y field), was given until the late 1980s as part of (sub)total nodal irradiation (Supplementary Figure 1). Since the late 1980s, a growing number of patients received more limited radiation fields. Information on radiation doses and fractionation schedules for individual patients was not routinely collected for all participating hospitals. From the late 1960 s to the 1980 s, chemotherapy consisted mainly of MOPP (mechlorethamine, vincristine, procarbazine, prednisone). In the 1980s, anthracycline-containing regimens such as MOPP/ABV (mechlorethamine, vincristine, procarbazine, prednisone/doxorubicin, bleomycin, vinblastine) and ABVD (doxorubicin, bleomycin, vinblastine, dacarbazine) were introduced.

Statistical analysis. Colorectal cancer incidence in the cohort was compared with age-, sex-, subsite and calendar period-specific CRC incidence rates in the Dutch population, accounting for personyears of observation. The cancer incidence data from the Eindhoven Cancer Registry up to 1988 and from the Netherlands Cancer Registry from 1989 onwards were used as reference (IKNL, 2012).

Time at risk began 5 years after the start of HL treatment and ended at the date of CRC diagnosis, date of death or date of most recent medical information, whichever came first. HL was the first primary malignancy in all patients. Patients who developed a subsequent malignancy within 5 -years after HL were excluded. All CRC diagnosed $\geqslant 5$ years after start of HL treatment were retained in the analyses. Standardized incidence ratios (SIRs) were calculated as the ratios of the observed and expected numbers of 
CRC in the cohort, and absolute excess risks (AERs) as the observed numbers of CRC in our cohort minus the expected numbers, divided by number of person-years at risk, multiplied by 10000 . Standardized incidence ratios were calculated for any CRC and for colon cancer subsites and rectal cancer separately; analyses were performed by sex, age at first HL treatment, follow-up interval, and type of treatment. Prescribed cumulative procarbazine doses were estimated using standard procarbazine doses per cycle in each chemotherapy regimen as a measure for alkylating chemotherapy dose; that is, three cycles of MOPP or six cycles of MOPP-ABV are equivalent to a prescribed cumulative procarbazine dose of $4.2 \mathrm{~g} \mathrm{~m}^{-2}$ of body surface area. For 172 patients $(7.9 \%$ of chemotherapy-treated patients), the prescribed procarbazine dose was unknown. A multivariate single mean imputation approach was applied to account for missing procarbazine doses, under the missing at random assumption, using a multinomial logistic regression model. Variables used for imputation were sex, age, year and hospital at HL treatment, type of chemotherapy and number of cycles, and CRC occurrence (yes/ no). Confidence intervals for SIRs and tests for homogeneity and trend of SIRs were calculated using standard methods (Breslow Day, 1987).

The cumulative incidence of CRC was estimated in the presence of death as a competing risk. Multivariable Cox regression analyses were performed to quantify the effects of HL treatment on CRC risk with time since start of HL treatment as time-scale. The proportional hazard assumption was assessed using residual-based methods. Variables considered in this analysis were sex, age and HL treatment. Interaction between a procarbazine dose $>4.2 \mathrm{~g} \mathrm{~m}^{-2}$ and infradiaphragmatic radiation was assessed by evaluating departure from an additive model $\mathrm{HR}=1+\left(\beta_{1}\right.$ procarbazine $+\beta_{2}$ infraRT $) \times$ $\exp ^{(\beta 3(\text { procarbazine }+ \text { infraRT }))}$ or from a multiplicative model $\mathrm{HR}=$

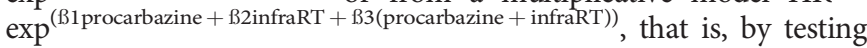
whether $\beta_{3}=0$ using a likelihood ratio test. Analyses were performed using STATA (STATA 13, Statacorp LP, College Station, TX, USA) and Epicure statistical software (Epicure, version 1.8, Hirosoft International, Seattle, WA, USA). A $P$-value $<0.05$ was considered statistically significant.

\section{RESULTS}

Patient characteristics. Median age at start of HL treatment was 27.3 years (interquartile range (IQR) 21.0-35.5; Table 1). Almost $50 \%$ had received infradiaphragmatic radiation therapy; $28 \%$ received chemotherapy and infradiaphragmatic radiation therapy combined. Chemotherapy mostly comprised of MOPP or MOPPlike chemotherapy; $35.8 \%$ of the patients treated with chemotherapy received $>4.2 \mathrm{~g} \mathrm{~m}^{-2}$ procarbazine-containing chemotherapy. Median follow-up was 22.9 years (IQR 16.7-30.7) and $23.4 \%$ of patients were followed $\geqslant 30$ years.

Fifty-five HL survivors developed CRC; 34 patients had colon cancer and 21 rectal cancer. Among the 52 CRC patients treated with radiation therapy, the CRC was located within the radiation field in $46 \%$ and outside in $42 \%$; for $12 \%$ this was unknown (Supplementary Table 1). The median time to CRC diagnosis was 22.9 years (IQR: 16.7-30.7) and median age at CRC diagnosis was 56.4 years (IQR: 50.6-62.2; Table 1). The youngest CRC patient was 35 years at diagnosis. Most CRCs were stage 2 (38\%) or higher (stage $3(24 \%)$ and stage 4 (15\%); Supplementary Table 1). At the end of follow-up, 43 CRC patients had died, of whom 17 (40\%) due to CRC. The 5-year overall survival after CRC diagnosis was $31 \%$.

CRC risk compared with the general population. HL survivors had a 2.4 -fold (95\% confidence interval (CI) 1.8-3.2) increased SIR of developing CRC compared with the general population, corresponding to 5.7 excess cases per 10000 patient-years
Table 1. General characteristics of all Hodgkin lymphoma patients and colorectal cancer (CRC) patients

\begin{tabular}{|c|c|c|c|c|}
\hline & Cohort & $\%$ & CRC cases & $\%$ \\
\hline All patients & 3121 & 100.0 & 55 & 100.0 \\
\hline $\begin{array}{l}\text { Sex } \\
\text { Men } \\
\text { Women }\end{array}$ & $\begin{array}{l}1776 \\
1345\end{array}$ & $\begin{array}{l}56.9 \\
43.1\end{array}$ & $\begin{array}{l}34 \\
21\end{array}$ & $\begin{array}{l}61.8 \\
38.2\end{array}$ \\
\hline $\begin{array}{l}\text { Age at first } \mathrm{HL} \text { treatment (years) } \\
\text { Median (IQR) } \\
<25^{\mathrm{a}} \\
25-34 \\
35-50\end{array}$ & $\begin{array}{c}27.3 \\
(21.0-35.5) \\
1284 \\
1009 \\
828\end{array}$ & $\begin{array}{l}41.2 \\
32.3 \\
26.5\end{array}$ & $\begin{array}{c}30.4 \\
(23.4-41.8) \\
17 \\
16 \\
22\end{array}$ & $\begin{array}{l}30.9 \\
29.1 \\
40.0\end{array}$ \\
\hline $\begin{array}{l}\text { Stage HL } \\
\text { I } \\
\text { II } \\
\text { III \& IV } \\
\text { Unknown }\end{array}$ & $\begin{array}{c}719 \\
1398 \\
795 \\
209\end{array}$ & $\begin{array}{r}23.0 \\
44.8 \\
25.5 \\
6.7\end{array}$ & $\begin{array}{l}12 \\
15 \\
16 \\
12\end{array}$ & $\begin{array}{l}21.8 \\
27.3 \\
29.1 \\
21.8\end{array}$ \\
\hline $\begin{array}{l}\text { Treatment period } \\
\text { 1965-1974 } \\
1975-1984 \\
1985-1995\end{array}$ & $\begin{array}{c}660 \\
1045 \\
1416\end{array}$ & $\begin{array}{l}21.1 \\
33.5 \\
45.4\end{array}$ & $\begin{array}{r}25 \\
23 \\
7\end{array}$ & $\begin{array}{l}45.5 \\
41.8 \\
12.7\end{array}$ \\
\hline $\begin{array}{c}\text { Follow-up (years) } \\
\text { Median (IQR) }\end{array}$ & $\begin{array}{c}22.9 \\
(16.7-30.7)\end{array}$ & & $\begin{array}{c}22.9 \\
(16.7-30.7)\end{array}$ & \\
\hline $\begin{array}{l}5-9 \\
10-19 \\
20-29 \\
\geqslant 30\end{array}$ & $\begin{array}{c}304 \\
869 \\
1218 \\
730\end{array}$ & $\begin{array}{r}9.8 \\
27.8 \\
39.0 \\
23.4\end{array}$ & $\begin{array}{r}2 \\
16 \\
21 \\
16\end{array}$ & $\begin{array}{r}3.6 \\
29.1 \\
38.2 \\
29.1\end{array}$ \\
\hline
\end{tabular}

\section{Treatment for $\mathrm{HL}$}

Treatment category ${ }^{b}$

CT only

Supradiaphragmatic RT, no CT Supradiaphragmatic RT + CT

Infra- \pm supradiaphragmatic RT, no CT Infra- \pm supradiaphragmatic RT + CT

Infradiaphragmatic irradiation ${ }^{\mathbf{b}}$

No infradiaphragmatic $\mathrm{RT}^{\mathrm{c}}$

PAO

$\mathrm{PAO}+$ spleen

Inverted $Y^{d} \pm$ spleen

Infradiaphragmatic other

CT regimen ${ }^{\mathbf{b}}$

No CT

MOPP or MOPP-like

$M O P P$ and $A B V D$

MOPP and ABV

EBVP

ABVD

Other $^{9}$

CT treatment according to cumulative

procarbazine dose ${ }^{h, b}$

No CT

Non-alkylating CT only

Alkylating $\mathrm{CT}$, no procarbazine

Alkylating CT, $\leq 4.2 \mathrm{~g} \mathrm{~m}^{-2}$

procarbazine

Alkylating $\mathrm{CT},>4.2-8.4 \mathrm{~g} \mathrm{~m}^{-2}$

procarbazine

Alkylating $\mathrm{CT}$, > $8.4 \mathrm{~g} \mathrm{~m}^{-2}$

procarbazine

$C T$, type unknown

Age at CRC diagnosis (years)

Median (IQR)

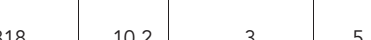

5.5

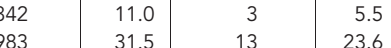

\begin{tabular}{l|l|l|l|}
879 & 28.1 & 27 & 49.1 \\
\hline
\end{tabular}

Abbreviations: $\mathrm{ABVD}=$ doxorubicin, bleomycin, vinblastine, dacarbazine; $\mathrm{CRC}=$ colorectal cancer; $C T=$ chemotherapy; $E B V P=$ epirubicine, bleomycin, vinblastine, prednisone; $H L=$ Hodgkin lymphoma; MOPP = mechlorethamine, vincristine, procarbazine, prednisone; MOPP$A B V(D)=$ mechlorethamine, vincristine, procarbazine, prednisone - doxorubicin, bleomycin, vinblastine, (dacarbazine); $\mathrm{PAO}=$ para-aortic; $\mathrm{IQR}=$ inter quartile range; $\mathrm{RT}=$ radiation therapy. $\mathrm{a}_{\text {In }}$ all, 218 patients (7.0\%) were younger than 15 years at $\mathrm{HL}$ diagnosis.

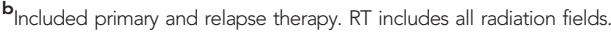

${ }^{c}$ No RT or supradiaphragmatic RT only.

$\mathbf{d}_{\text {Inverted }} \mathrm{Y}$ field consists of para-aortic and iliac nodes.

$\mathbf{e}_{\text {Include iliacal and inguinal fields. }}$

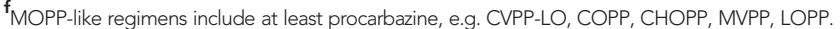

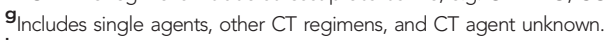

$\mathrm{h}_{\text {Mutually exclusive categories. }}$ 
Table 2. Risk of colorectal cancer after HL treatment: SIR, AER, and 20-year and 30-year cumulative incidence

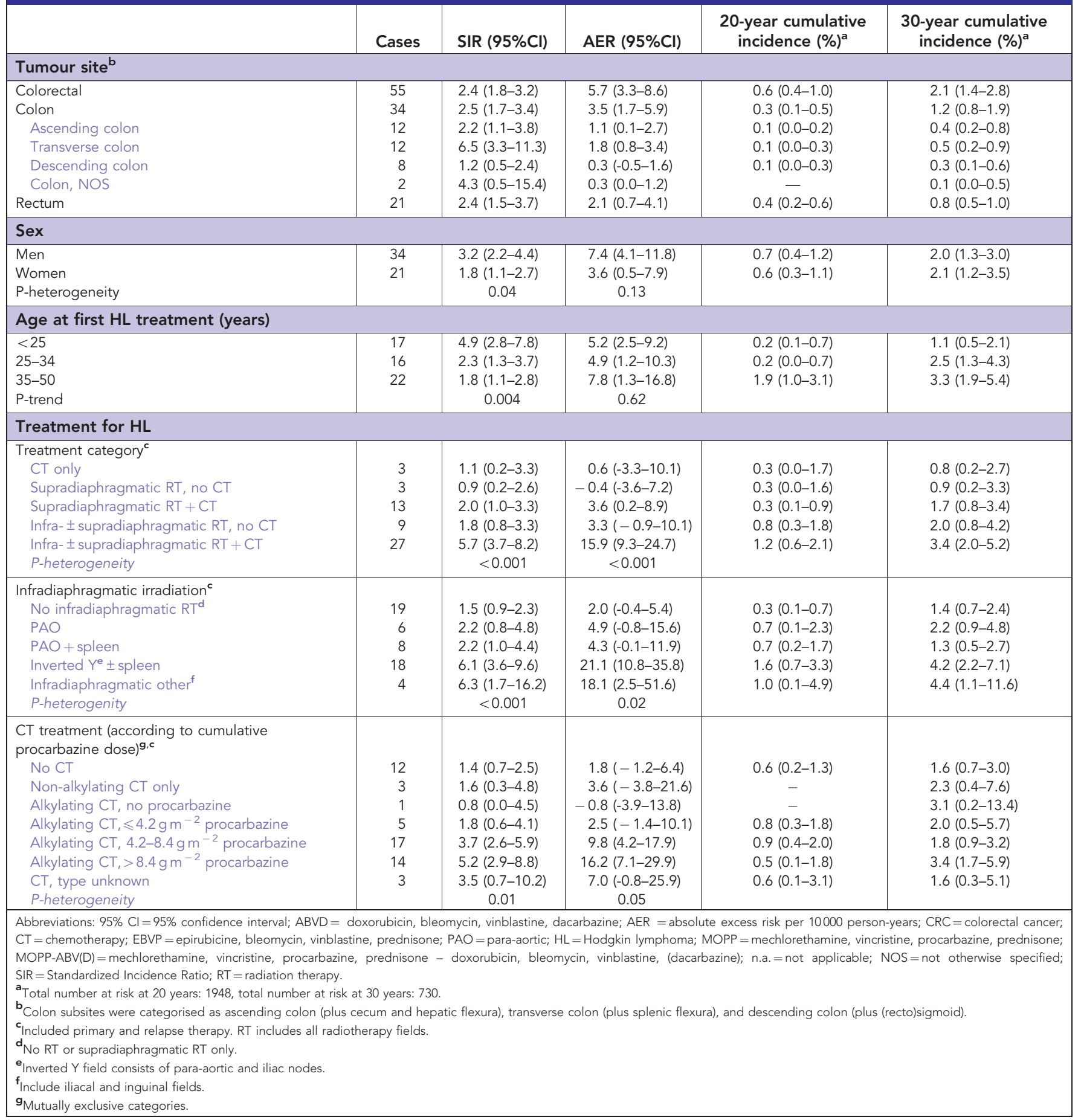

(Table 2). The SIRs of rectal and colon cancer were 2.4 (95\%CI: $1.5-3.7)$ and 2.5 (95\% CI: 1.7-3.4), respectively. While risks of transverse colon (SIR: 6.5; 95\%CI: 3.3-11.3) and ascending colon cancer (SIR: 2.2; 95\%CI: 1.1-3.8) were increased, the risk of descending colon cancer was not (SIR: 1.2, 95\%CI: 0.5-2.4). The SIR was slightly higher in men (SIR: 3.2, 95\% CI: 2.2-4.4) than in women (SIR: 1.8, 95\% CI: 1.1-2.7; p-heterogeneity: 0.04).

Colorectal cancer risk by age at first and time since HL treatment. The SIR of CRC was highest for patients treated $<25$ years of age (SIR: $4.9 ; 95 \% \mathrm{CI}: 2.8-7.8$ compared to $1.8 ; 95 \% \mathrm{CI}$ : $1.1-2.8$, for patients $35-50$ years; p-trend 0.004 , Table 3 ). However, while for colon cancer, the SIRs decreased with older age at HL treatment (SIRs were 6.8 and 1.3 for patients treated $<25$ years or at age 35-50 years, respectively; p-trend $<0.001$ ), this was not the case for rectal cancer (SIRs were 2.1 and 2.6 for patients treated $<25$ years or at age 35-50 years, respectively; $\mathrm{p}$-trend $0.90)$.

The SIR of CRC was elevated from 10 years after treatment and remained increased with longer follow-up duration, with SIRs of 2.3 (95\%CI: $1.3-3.7)$ at $10-19$ years and 2.8 (95\%CI: $1.6-4.6)$ at $\geq 30$ years of follow-up ( $p$-trend $=0.29$ ). The AER of CRC increased steadily with longer follow-up duration ( $\mathrm{p}$-trend $<0.001$ ); the AER was 3.6 at $10-19$ years and 24.6 per 10000 patients-years at $\geqslant 30$ years of follow-up, respectively (data not shown). 
Table 3. Risks of colorectal cancer after HL treatment; SIRs by sex, age, follow-up interval and treatment

\begin{tabular}{|c|c|c|c|c|c|c|c|c|c|c|c|c|}
\hline \multirow[b]{2}{*}{ Tumour site } & \multicolumn{3}{|c|}{ All colon sites $(n=34)$} & \multicolumn{3}{|c|}{ Transverse colon $^{\mathrm{a}}(\mathrm{n}=12)$} & \multicolumn{3}{|c|}{ Colon other ${ }^{\mathrm{b}}(n=22)$} & \multicolumn{3}{|c|}{ Rectum $(n=21)$} \\
\hline & 0 & SIR & $95 \% \mathrm{Cl}$ & 0 & SIR & $95 \% \mathrm{Cl}$ & O & SIR & $95 \% \mathrm{Cl}$ & 0 & SIR & $95 \% \mathrm{Cl}$ \\
\hline \multicolumn{13}{|l|}{ Risk factor } \\
\hline \multicolumn{13}{|l|}{ Sex } \\
\hline Men & 23 & 3.3 & $2.1-5.0$ & 8 & 8.5 & $3.7-16.7$ & 15 & 2.4 & $1.4-4.0$ & 11 & 2.9 & $1.5-5.2$ \\
\hline Women & 11 & 1.6 & $0.8-2.9$ & 4 & 4.4 & $1.2-11.2$ & 7 & 1.1 & $0.5-2.3$ & 10 & 2.0 & $1.0-3.7$ \\
\hline \multicolumn{13}{|l|}{ Age at first $\mathrm{HL}$ treatment (years) } \\
\hline$<25$ & 14 & 6.8 & $3.7-11.3$ & 6 & 19.3 & $7.1-42.0$ & 8 & 4.2 & $1.8-8.2$ & 3 & 2.1 & $0.4-6.1$ \\
\hline $25-34$ & 10 & 2.4 & $1.2-4.4$ & 3 & 5.3 & $1.1-15.6$ & 7 & 1.9 & $0.7-3.8$ & 6 & 2.2 & $0.8-4.7$ \\
\hline $35-50$ & 10 & 1.3 & $0.6-2.4$ & 3 & 3.1 & $0.6-18.9$ & 7 & 1.0 & $0.4-2.2$ & 12 & 2.6 & $1.4-4.6$ \\
\hline \multicolumn{13}{|l|}{ Follow-up period (years) } \\
\hline $5-9$ & 1 & 1.0 & $0.0-5.3$ & 0 & - & - & 1 & 0.9 & $0.0-5.2$ & 1 & 1.4 & $0.0-7.9$ \\
\hline $10-19$ & 7 & 1.7 & $0.7-3.4$ & 4 & 6.7 & $1.8-17.3$ & 3 & 0.8 & $0.2-2.3$ & 9 & 3.2 & $1.5-6.1$ \\
\hline $20-29$ & 14 & 2.8 & $1.5-4.7$ & 5 & 8.1 & $2.6-18.9$ & 9 & 2.1 & $0.9-3.9$ & 7 & 2.2 & $0.9-4.6$ \\
\hline$\geqslant 30$ & 12 & 3.4 & $1.7-5.9$ & 3 & 7.0 & $1.4-20.4$ & 9 & 2.9 & $1.3-5.4$ & 4 & 1.9 & $0.5-4.9$ \\
\hline \multicolumn{13}{|l|}{ Treatment for $\mathrm{HL}^{\mathrm{c}}$} \\
\hline \multicolumn{13}{|l|}{ Treatment category $^{c}$} \\
\hline CT only & 1 & 0.6 & $0.0-3.4$ & 0 & - & - & 1 & 0.7 & $0.0-3.8$ & 2 & 2.0 & $0.2-7.3$ \\
\hline Supradiaphragmatic RT, no CT & 2 & 1.0 & $0.1-3.5$ & 1 & 3.5 & $0.1-19.5$ & 1 & 0.5 & $0.0-3.0$ & 1 & 0.8 & $0.0-4.3$ \\
\hline Supradiaphragmatic $\mathrm{RT}+\mathrm{CT}$ & 8 & 2.0 & $0.9-3.9$ & 1 & 1.9 & $0.0-10.4$ & 7 & 1.9 & $0.8-4.0$ & 5 & 1.9 & $0.6-4.5$ \\
\hline Infra- \pm supradiaphragmatic RT, no CT & 7 & 2.2 & $0.9-4.6$ & 2 & 4.9 & $0.6-17.6$ & 5 & 1.8 & $0.6-4.2$ & 2 & 1.0 & $0.1-3.6$ \\
\hline Infra- \pm supradiaphragmatic $\mathrm{RT}+\mathrm{CT}$ & 16 & 5.5 & $3.1-8.9$ & 8 & 19.6 & $8.5-38.6$ & 8 & 3.0 & $1.3-6.0$ & 11 & 5.9 & $2.9-10.5$ \\
\hline \multicolumn{13}{|l|}{ Infradiaphragmatic irradiation $^{c}$} \\
\hline No infradiaphragmatic $\mathrm{RT}^{d}$ & 11 & 1.4 & $0.7-2.5$ & 2 & 1.9 & $0.2-7.0$ & 9 & 1.3 & $0.6-2.5$ & 8 & 1.6 & $0.7-3.2$ \\
\hline PAO & 5 & 3.0 & $1.0-7.1$ & 2 & 8.8 & $1.1-32.0$ & 3 & 2.0 & $0.4-5.8$ & 1 & 0.9 & $0.0-5.2$ \\
\hline $\mathrm{PAO}+$ spleen & 5 & 2.3 & $0.8-5.4$ & 4 & 14.0 & $3.8-35.8$ & 1 & 0.5 & $0.0-2.9$ & 3 & 2.1 & $0.4-6.1$ \\
\hline Inverted $Y^{\mathbf{e}} \pm$ spleen & 11 & 6.0 & $3.0-10.7$ & 4 & 15.9 & $4.3-40.8$ & 7 & 4.2 & $1.7-8.7$ & 7 & 6.3 & $2.5-13.0$ \\
\hline Infradiaphragmatic other & 2 & 5.2 & $0.6-18.9$ & - & - & - & 2 & 5.7 & $0.7-20.7$ & 2 & 8.1 & $1.0-29.1$ \\
\hline \multicolumn{13}{|l|}{$\begin{array}{l}\text { CT treatment according to cumulative } \\
\text { procarbazine dose } e^{\text {, f }}\end{array}$} \\
\hline No CT & 9 & 1.7 & $0.8-3.3$ & 3 & 4.3 & $0.9-12.6$ & 6 & 1.3 & $0.5-2.8$ & 3 & 0.9 & $0.2-2.7$ \\
\hline Non-alkylating CT only & 2 & 1.8 & $0.2-6.4$ & 0 & - & - & 2 & 2.0 & $0.2-7.1$ & 1 & 1.4 & $0.0-8.0$ \\
\hline Alkylating $C T$, no procarbazine & 0 & - & - & 0 & - & - & 0 & - & - & 1 & 2.0 & $0.1-11.4$ \\
\hline Alkylating $C T, \leqslant 4.2 \mathrm{~g} \mathrm{~m}^{-2}$ procarbazine & 3 & 1.7 & $0.4-5.1$ & 1 & 4.4 & $0.1-24.7$ & 2 & 1.3 & $0.2-4.7$ & 2 & 1.8 & $0.2-6.4$ \\
\hline Alkylating CT, $4.2-8.4 \mathrm{~g} \mathrm{~m}^{-2}$ procarbazine & 7 & 2.5 & $1.0-5.2$ & 2 & 5.4 & $0.7-19.5$ & 5 & 2.0 & $0.6-4.6$ & 10 & 5.6 & $2.7-10.3$ \\
\hline Alkylating $C T,>8.4 \mathrm{~g} \mathrm{~m}^{-2}$ procarbazine & 10 & 6.1 & $2.9-11.2$ & 5 & 21.9 & $7.1-51.0$ & 5 & 3.3 & $1.1-7.8$ & 4 & 3.9 & $1.1-9.9$ \\
\hline $\mathrm{CT}$, type unknown & 3 & 5.6 & $1.2-16.4$ & 1 & 13.3 & $0.3-74.2$ & 2 & 4.1 & $0.5-14.8$ & 0 & - & - \\
\hline Alkylating $\mathrm{CT},>4.2 \mathrm{~g} \mathrm{~m}^{-2}$ procarbazine & 17 & 3.8 & $2.2-6.1$ & 7 & 11.7 & $4.7-24.1$ & 10 & 2.5 & $1.2-4.8$ & 14 & 5.0 & $2.7-8.3$ \\
\hline \multicolumn{13}{|c|}{ 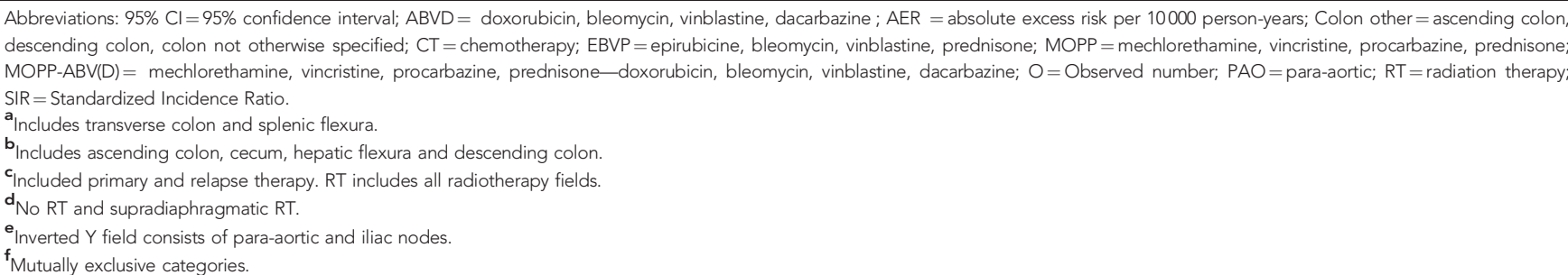 } \\
\hline
\end{tabular}

Treatment-specific CRC risk compared to the general population. The SIR of CRC was not increased in patients treated with chemotherapy only or supradiaphragmatic radiation therapy only (Table 2). Patients treated with supradiaphragmatic radiation therapy and chemotherapy had a 2.0-fold increased CRC risk (95\%CI: 1.0-3.3). Infradiaphragmatically irradiated patients not treated with chemotherapy had a nonsignificantly increased risk of CRC (SIR: 1.8, 95\%CI: 0.8-3.3). The highest SIR of CRC was observed in patients who received infradiaphragmatic radiation therapy and chemotherapy (SIR: 5.7, 95\%CI: 3.7-8.2), translating into an AER of 15.9 per 10000 patient-years. Patients treated with para-aortic fields had a 3.0-fold increased (95\%CI: $1.0-7.1)$ risk of colon cancer. Risk of transverse colon cancer was even 15.9-fold increased (95\%CI: 4.3-40.8) after treatment with an inverted-Y field (Table 3). The highest SIR of rectal cancer was observed following treatment with inverted-Y fields (SIR: 6.3, 95\%CI: 2.513.0). Patients treated with $>4.2 \mathrm{~g} \mathrm{~m}^{-2}$ procarbazine had a strongly increased risk of developing CRC compared with the general population (SIR: 4.3, 95\%CI: 2.9-6.1).
Risk factors for CRC: multivariable regression analysis. In multivariable Cox analyses (Table 4), infradiaphragmatic radiation therapy was associated with increased CRC risk (age- and sexadjusted hazard ratio (HR) 2.8, 95\%CI: 1.6-4.9). Patients treated with a procarbazine dose $>4.2 \mathrm{~g} \mathrm{~m}^{-2}$ also had an increased CRC-risk (HR: 3.3, 95\%CI: 1.8-6.2) compared to patients receiving $\leqslant 4.2 \mathrm{~g} \mathrm{~m}^{-2}$ of procarbazine. A very high CRC risk was seen for patients who had received both a procarbazine dose $>4.2 \mathrm{~g} \mathrm{~m}^{-2}$ and infradiaphragmatic radiation therapy (HR: 6.8, 95\% CI: 3.0-15.6, compared with patients receiving none of these treatments). The combined effect of prescribed procarbazine dose and infradiaphragmatic radiation therapy showed departure from additivity $\left(p_{\text {additivity }}=0.0043\right.$ ), pointing to a synergistic effect of procarbazine and infradiaphragmatic radiation therapy. The data did not support a supermultiplicative joint effect ( $p_{\text {multiplicativity }}=0.153$ ). This combined effect of a prescribed procarbazine dose $>4.2 \mathrm{~g} \mathrm{~m}^{-2}$ and infradiaphragmatic radiation therapy was stronger for transverse colon and rectal cancer, which were more often located in the radiation fields (HR: 10.1, 95\%CI: 3.3-30.7). 
A

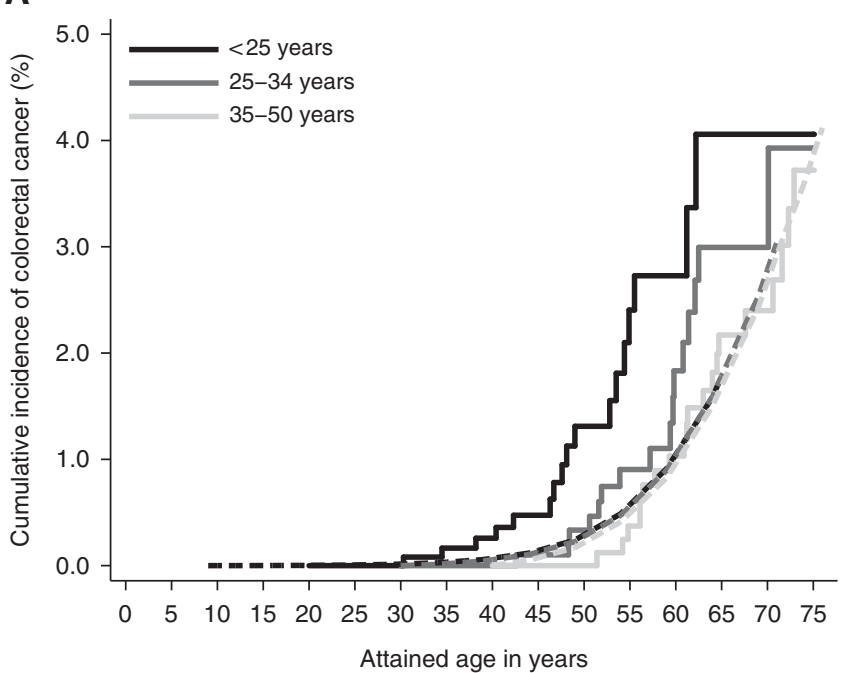

B

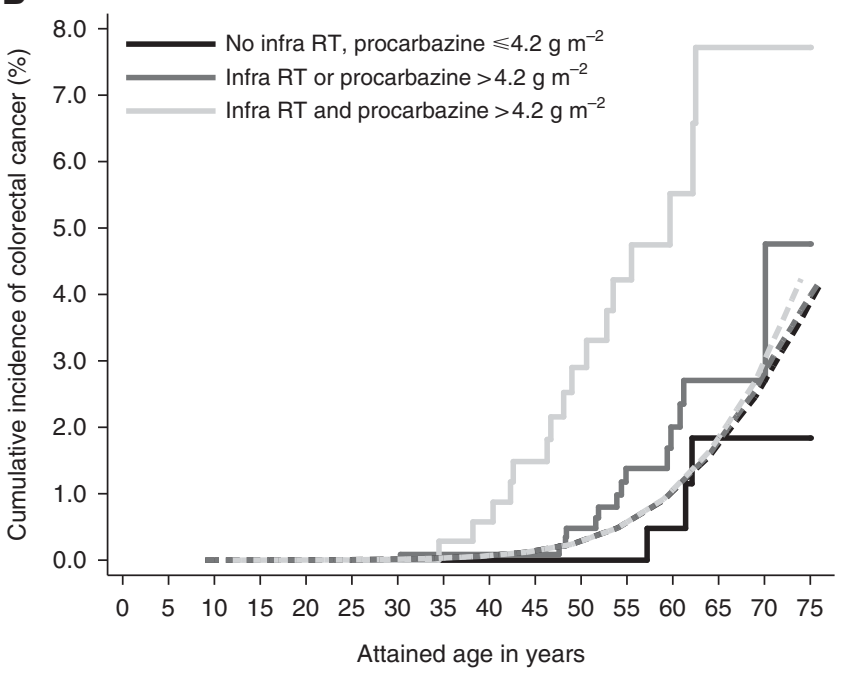

Figure 1. (A) Cumulative incidence of CRC by attained age according to age at first Hodgkin lymphoma treatment. Solid lines represent the observed incidence, dashed lines the expected incidence.

(B) Cumulative incidence of CRC by attained age according to radiation therapy and procarbazine dose for $\mathrm{HL}$ patients treated before the age of 35 . Solid lines represent the observed incidence, dashed lines the expected incidence. Infra RT = infradiaphragmatic radiotherapy.

Morton et al, 2013). Nottage and colleagues observed that alkylating agent exposure was associated with an almost nine-fold increased risk of CRC; associations with specific agents were not reported (Nottage et al, 2012). In the study by Henderson and colleagues, high-dose procarbazine exposure was independently associated with an increased risk of gastrointestinal malignancies in childhood cancer survivors treated with abdominal radiation, while exposure to procarbazine without abdominal radiation was not associated with gastrointestinal malignancies (Henderson et al, 2012).

Because procarbazine and mechlorethamine (and other components of MOPP- and MOPP-like regimens) were highly correlated (of 1.864 patients treated with procarbazine, 131 (7.0\%) did not receive mechlorethamine, while procarbazine and mechlorethamine dose-groups were discordant for only 52 (2.8\%) patients), we could not disentangle the effects of both drugs. We attribute the observed increased risk to procarbazine in presentation of our results because procarbazine is given orally and possibly comes in direct contact with colon mucosa and has been implicated in stomach carcinogenesis in previous papers van (van den BeltDusebout et al, 2009; Morton et al, 2013).

In accordance with other studies of second solid malignancy risk among HL patients, in our study, CRC relative risk was higher for patients treated at younger ages (Swerdlow et al, 2000; Dores et al, 2002; Hodgson et al, 2007; Schaapveld et al, 2015). However, when evaluating colon and rectum separately, the SIR of rectal cancer was not much affected by age, while colon cancer risk behaved more in line with a radiation-associated pattern, such as observed for breast (van Leeuwen et al, 2000), lung (Swerdlow et al, 2000) and stomach (van den Belt-Dusebout et al, 2009) cancer, also showing the highest SIRs among patients exposed to radiation at the very young ages.

Strengths of our study are the large size of the cohort, the detailed information on HL treatment and the long and complete follow-up for second malignancies. However, despite the large size of our cohort, the number of CRC cases was still rather low for a detailed assessment of the association of $\mathrm{HL}$ treatment and subsequent CRC risk. Given the large number of comparisons made in our paper we caution against over-interpretation of our findings, especially when based on small number of events. We had no information on common risk factors for CRC such as family history of CRC.

Surveillance bias is an unlikely explanation for the increased CRC risk in our study, as there have been no CRC surveillance recommendations in HL survivors. Furthermore, CRC screening in the Dutch general population was only introduced in January 2014.

Since HL patients nowadays only rarely receive high-dose procarbazine in combination with infradiaphragmatic radiotherapy, we expect that CRC risk following HL will decrease. Although most patients in our cohort were treated decades ago, often with treatment regimens now considered outdated, evaluation of longterm effects of these treatments remains relevant and our findings have important implications for HL patients treated in the past. Since HL predominantly occurs at young ages, the cohort of HL survivors treated in the 1960s-1980s has only recently reached the ages at which CRC commonly occurs in the general population. Importantly, our data do not show that CRC risk levels off after longer follow-up duration. When considering more intensive CRC surveillance in HL survivors we must realise, however, that we do not know whether the pathogenesis of treatment-induced CRC in HL survivors is similar to that of CRC in the general population. As in the general population, most CRCs among HL survivors were adenocarcinomas and it appears that treatment-induced CRCs are preceded by adenomas as well (Rigter et al, 2016; Rigter et al, 2017). Currently, most screening guidelines for HL survivors do not yet include CRC screening. The Children's Oncology Group does recommend that childhood cancer survivors exposed to $>30 \mathrm{~Gy}$ of abdominal radiation have a colonoscopy at least every 5 years, starting at the age of 35 , or 10 years after radiation, whichever occurs last (Children's Oncology Group, 2008). On the basis of our results, also in view of the unfavourable stage distribution and low 5-year overall survival rate, we think that CRC surveillance should be considered in HL survivors who received high-dose procarbazine and infradiaphragmatic radiation therapy, starting 10 years after first treatment but not before the age of 35 years.

\section{ACKNOWLEDGEMENTS}

We thank the Netherlands nationwide network and registry of histo- and cytopathology (PALGA) as well as the registration teams of the Netherlands Comprehensive Cancer Organisation (IKNL) for the collection of the data for the Netherlands Cancer Registry 
and the scientific staff of the Netherlands Comprehensive Cancer Organisation. This work was supported by the Dutch Cancer Society (Koningin Wilhelmina Fonds, grant number NKI 2010-4720).

\section{CONFLICT OF INTEREST}

The authors declare no conflict of interest.

\section{REFERENCES}

Birdwell SH, Hancock SL, Varghese A, Cox RS, Hoppe RT (1997) Gastrointestinal cancer after treatment of Hodgkin's disease. Int J Rad Oncol Biol Phys 37: 67-673.

Breslow NE, Day NE (1987) Statistical methods in cancer research. Volume II-The design and analysis of cohort studies. IARC Sci Publ 82: 1-406.

Casparie M, Tiebosch ATMG, Burger G, Blauwgeers H, Van de Pol A, van Krieken JHJ, Meijer GA (2007) Pathology databanking and biobanking in The Netherlands, a central role for PALGA, the nationwide histopathology and cytopathology data network and archive. Cell Oncol 29(1): 19-24.

De Bruin ML, Burgers JA, Baas P, van't Veer MB, Noordijk EM, Louwman MW, Zijlstra JM, van den Berg H, Aleman BM, van Leeuwen FE (2009) Malignant mesothelioma after radiation treatment for Hodgkin lymphoma. Blood 113(16): 3679-3681.

De Bruin ML, Sparidans J, van 't Veer MB, Noordijk E, Louwman MW, Zijlstra JM, van den Berg H, Russell N, Broeks A, Baaijens MH, Aleman BM, van Leeuwen FE (2009) Breast cancer risk in female survivors of Hodgkin's lymphoma; lower risk after smaller radiation volumes. J Clin Oncol 27(26): 4229-4231.

Dores GM, Curtis RE, van Leeuwen FE, Stovall M, Hall P, Lynch CF, Smith SA, Weathers RE, Storm HH, Hodgson DC, Kleinerman RA, Joensuu H, Johannesen TB, Andersson M, Holowaty EJ, Kaijser M, Pukkala E, Vaalavirta L, Fossa SD, Langmark F, Travis LB, Fraumeni JF, Aleman BM, Morton LM, Gilbert ES (2014) Pancreatic cancer risk after treatment for Hodgkin lymphoma. Ann Oncol 25: 2073-2079.

Dores GM, Metayer C, Curtis RE, Lynch CF, Clarke EA, Glimelius B, Storm H, Pukkala E, van Leeuwen FE, Holowaty EJ, Andersson M, Wiklund T, Joensuu T, van/'t Veer MB, Stovall M, Gospodarowicz M, Travis LB (2002) Second malignant neoplasms among long-term survivors of Hodgkin's disease: a population-based evaluation over 25 years. J Clin Oncol 20: 3484-3494.

Favier O, Heutte N, Stamatoullas-Bastard A, Carde P, Van't Veer MB, Aleman BM, Noordijk EM, Thomas J, Ferme C, Henry-Amar M. European Organization for R, Treatment of Cancer Lymphoma Gthe Groupe d'Etudes des Lymphomes de 1A (2009) Survival after Hodgkin lymphoma: causes of death and excess mortality in patients treated in 8 consecutive trials. Cancer 115(8): 1680-1691.

Children's Oncology Group (2008) Children's Oncology Group Long-Term Follow-up Guidelines for Survivors of Childhood, Adolescent, and Young Adult Cancers. Children's Oncology Group: Arcadia, CA, USA.

Henderson TO OK, Whitton J, Leisenring W, Neglia J, Meadows A, Crotty C, Rubin DT, Diller L, Inskip P, Smith SA, Stovall M, Constine LS, Hammond S, Armstrong GT, Robison LL, Nathan PC (2012) Secondary gastrointestinal cancer in childhood cancer survivors: a cohort study. Ann Intern Med 156(11): 757-766.

Hodgson DC, Gilbert ES, Dores GM, Schonfeld SJ, Lynch CF, Storm H, Hall P, Langmark F, Pukkala E, Andersson M, Kaijser M, Joensuu H, Fossa SD, Travis LB (2007) Long-term solid cancer risk among 5-year survivors of Hodgkin's lymphoma. J Clin Oncol 25: 1489-1497.

IKNL (2012) Netherlands Comprehensive Cancer Organisation (IKNL); Dutch Cancer Figures. Available at: http://cijfersoverkanker.nl.

Land CE (1986) Carcinogenic effects of radiation on the human digestive tract and other organs. In Radiation Carcinogenesis, Upton AC, Albert RE, Burns F, Shore RE (eds) Vol. 373, pp 347-378. Elsevier: New York, NY, USA.

Lemmens V, Steenbergen Lv, Janssen-Heijnen M, Martijn H, Rutten H, Coebergh JW (2010) Trends in colorectal cancer in the south of the Netherlands 1975-2007: rectal cancer survival levels with colon cancer survival. Acta Oncol 49(6): 784-796.
Morton LM, Dores GM, Curtis RE, Lynch CF, Stovall M, Hall P, Gilbert ES, Hodgson DC, Storm HH, Johannesen TB, Smith SA, Weathers RE, Andersson M, Fossa SD, Hauptmann M, Holowaty EJ, Joensuu H, Kaijser M, Kleinerman RA, Langmark F, Pukkala E, Vaalavirta L, van den Belt-Dusebout AW, Fraumeni JF, Travis LB, Aleman BM, van Leeuwen FE (2013) Stomach cancer risk after treatment for Hodgkin Lymphoma. J Clin Oncol 31(27): 3369-3377.

Nakachi K, Harris CC, Tahara E (2006) Japan-US Cooperative Cancer Research Seminar on molecular epidemiological characteristics of lung and colon cancer development among atomic-bomb survivors, Bethesda, USA, February 23-24, 2006. Cancer Sci 97(11): 1279-1282.

Nakatsuka H, Shimizu Y, Yamamoto T, Sekine I, Ezaki H, Tahara E, Takahashi M, Shimoyama T, Mochinaga N, Tomita M (1992) Colorectal cancer incidence among atomic bomb survivors, 1950-80. J Radiat Res 33(4): 342-361.

Network (2012) The Cancer Genome Network. Comprehensive molecular characterization of human colon and rectal cancer. In Nature Vol. 487, pp 330-337.

Ng AK, Bernardo MV, Weller E, Backstrand K, Silver B, Marcus KC, Tarbell NJ, Stevenson MA, Friedberg JW, Mauch PM (2002) Second malignancy after Hodgkin disease treated with radiation therapy with or without chemotherapy: long-term risks and risk factors. Blood 100(6): 1989-1996.

Nottage K, McFarlane J, Krasin MJ, Li C, Srivastava D, Robison LL, Hudson MM (2012) Secondary colorectal carcinoma after childhood cancer. J Clin Oncol 30(20): 2552-2558.

Preston DL, Ron E, Tokuoka S, Funamoto S, Nishi N, Soda M, Mabuchi K, Kodama K (2007) Solid cancer incidence in atomic bomb survivors: 1958-1998. Radiat Res 168(1): 1-64.

Reulen RC, Frobisher C, Winter DL, Kelly J, Lancashire ER, Stiller CA, Pritchard-Jones K, Jenkinson HC, Hawkins MM. British Childhood Cancer Survivor Study Steering Group (2011) Long-term risks of subsequent primary neoplasms among survivors of childhood cancer. JAMA 305(22): 2311-2319.

Rigter LS, Kallenberg FG, Bastiaansen B, van Os TA, van Leeuwen FE, van Leerdam ME, Dekker E (2016) A case series of intestinal adenomatous polyposis of unidentified etiology; a late effect of irradiation? BMC Cancer 16(1): 862.

Rigter LS, Spaander MC, Moons LM, Bisseling TM, Aleman BM, de Boer JP, Lugtenburg PJ, Janus CP, Petersen EJ, Roesink JM, Raemaekers JM, van der Maazen RW, Cats A, Bleiker EM, Snaebjornsson P, Carvalho B, Lansdorp-Vogelaar I, Jóźwiak K, Te Riele H, Meijer GA, van Leeuwen FE, van Leerdam ME (2017) Colorectal cancer surveillance in Hodgkin lymphoma survivors at increased risk of therapy-related colorectal cancer: study design. BMC Cancer 17(1): 112.

Schaapveld M, Aleman BMP, van Eggermond AM, Janus CPM, Krol ADG, van der Maazen RWM, Roesink J, Raemaekers JMM, de Boer JP, Zijlstra JM, van Imhoff GW, Petersen EJ, Poortmans PMP, Beijert M, Lybeert ML, Mulder I, Visser O, Louwman MWJ, Krul IM, Lugtenburg PJ, van Leeuwen FE (2015) Second cancer risk up to 40 years after treatment for hodgkin's lymphoma. N Eng J Med 373(26): 2499-2511.

Schottenfeld D, Winawer SJ (1982) Large intestine. In Cancer Epidemiology and Prevention, Schottenfeld D, Fraumeni JFJ (eds), pp 703-727. W.B. Saunders: Philadelphia, PA, USA.

Schouten LJ, Straatman H, Kiemeney LA, Gimbrère CH, Verbeek AL (1994) The capture-recapture method for estimation of cancer registry completeness: a useful tool? Int J Epidemiol 23(6): 1111-1116.

Swerdlow AJ, Barber JA, Hudson GV, Cunningham D, Gupta RK, Hancock BW, Horwich A, Lister TA, Linch DC (2000) Risk of second malignancy after Hodgkin's disease in a collaborative British cohort: the relation to age at treatment. J Clin Oncol 18(3): 498-509.

Swerdlow AJ, Cooke R, Bates A, Cunningham D, Falk SJ, Gilson D, Hancock BW, Harris SJ, Horwich A, Hoskin PJ, Linch DC, Lister TA, Lucraft HH, Radford JA, Stevens AM, Syndikus I, Williams MV (2012) Breast cancer risk after supradiaphragmatic radiotherapy for Hodgkin's lymphoma in England and Wales: A National Cohort Study. J Clin Oncol 30(22): 2745-2752.

Swerdlow AJ, Higgins CD, Smith P, Cunningham D, Hancock BW, Horwich A, Hoskin PJ, Lister TA, Radford JA, Rohatiner AZS, Linch DC (2011) Second cancer risk after chemotherapy for hodgkin's lymphoma: A Collaborative British Cohort Study. J Clin Oncol 29(31): 4096-4104. 
Swerdlow AJ, Schoemaker MJ, Allerton R, Horwich A, Barber JA, Cunningham D, Lister TA, Rohatiner AZ, Vaughan Hudson G, Williams MV, Linch DC (2001) Lung cancer after Hodgkin's disease: a nested case-control study of the relation to treatment. J Clin Oncol 19(6): $1610-1618$.

Travis LB, Gospodarowicz M, Curtis RE, Clarke EA, Andersson M, Glimelius B, Joensuu T, Lynch CF, van Leeuwen FE, Holowaty E, Storm H, Glimelius I, Pukkala E, Stovall M, Fraumeni Jr JF, Boice Jr JD, Gilbert E (2002) Lung cancer following chemotherapy and radiotherapy for Hodgkin's disease. J Natl Cancer Inst 94(3): 182-192.

Travis LB, Hill DA, Dores GM, Gospodarowicz M, van Leeuwen FE, Holowaty E, Glimelius B, Andersson M, Wiklund T, Lynch CF, van't Veer MB, Glimelius I, Storm H, Pukkala E, Stovall M, Curtis R, Boice Jr. JD, Gilbert E (2003) Breast cancer following radiotherapy and chemotherapy among young women with Hodgkin's disease. JAMA 290(4): 465-475.

van den Belt-Dusebout AW, Aleman BM, Besseling G, de Bruin ML, Hauptmann M, van 't Veer MB, de Wit R, Ribot JG, Noordijk EM, Kerst
JM, Gietema JA, van Leeuwen FE (2009) Roles of radiation dose and chemotherapy in the etiology of stomach cancer as a second malignancy. Int J Rad Oncol Biol Phys 75(5): 1420-1429.

van Leeuwen FE, Klokman WJ, van 't Veer MB, Hagenbeek A, Krol AD, Vetter UA, Schaapveld M, van Heerde P, Burgers JM, Somers R, Aleman BM (2000) Long-term risk of second malignancy in survivors of Hodgkin's disease treated during adolescence or young adulthood. J Clin Oncol 18(3): 487-497.

WHO (2000) World Health Organization. International Classification of Diseases for Oncology. Organization WH (eds) 3rd edn. WHO, Geneva, Switzerland.

This work is published under the standard license to publish agreement. After 12 months the work will become freely available and the license terms will switch to a Creative Commons AttributionNonCommercial-Share Alike 4.0 Unported License.

Supplementary Information accompanies this paper on British Journal of Cancer website (http://www.nature.com/bjc) 